\title{
Application of Computer Aided Design in Industrial Product Design
}

\author{
Shi Yichun \\ Department of Information Engineering, Jiangsu Union Technical Institute, Nanjing, Jiangsu, 210000, China \\ email: 75191182@qq.com
}

Keywords: Computer Aided Design, Industrial Product Design, Applied Research

\begin{abstract}
With the rapid development of computer technology, computer aided design has been widely used in industrial product design. With the help of computer technology, industrial product design can be completed more conveniently and efficiently. With the support of strong data resources, the ideas of industrial product designers have also been expanded, and the ability of design innovation has been significantly improved.
\end{abstract}

\section{Summary of Computer-Aided Technologies}

The industrial design industry is developing and perfecting continuously with the help of computer technology, in the future, computer aided technology will become the mainstream technology of industrial design. With the continuous innovation of data technology, intelligent technology, network technology and so on, computer aided design in industrial product design, but also expand the scope of application, from industrial product design to development, a series of industrial design process are computer aided design figure, computer technology plays a decisive role in the development of industrial design industry.

(1) Data technology in computer aided technology

The data technology in computer-aided technology is based on the information-based database construction as the core, so that the computer can extract and process the industrial product design in a large number of industrial data, and provide the data content required by the designer. The computer-aided design process is the deep mining process of data. With the advent of the information age, it has given the industrial industry a powerful impetus for innovation in product design, and data mining has become the main computer-aided way in modern industrial product design, which has been widely used in industrial product design in recent years.

(2) Network technology in computer aided technology

The network technology in computer aided technology has been widely popularized in all walks of life in modern society. The close combination of Internet technology and computer technology provides sufficient design resources for the development of industrial product design [1]. With the help of computer and Internet technology, industrial product designers can quickly search and query industrial product information, which has brought great changes to industrial product design. Using the data exchange function and communication transmission function of network technology, the application convenience of computer aided design in industrial product design is convenient.

(3) Computational techniques in computer aided technology

With the development of information technology, computer aided technology has made remarkable progress. From the traditional computer computing mode to cloud computing mode, the speed, accuracy and reliability of computing have been greatly leapfrogged. Cloud computing is a new technology based on computer technology and network technology. Cloud computing takes cloud space as the medium, which can provide a broader information computing and information storage platform for industrial industry, and provide dynamic, extensible and virtual resources for industrial product designers. With the rapid development of cloud computing technology, cloud computing service capacity is also constantly increasing, in the computer-aided conditions of industrial product design, has a broad application prospects. 
(4) Intelligent technology in computer aided technology

The intelligent technology in computer-aided technology is a kind of technology which makes the computer have the ability of simulating human thinking by using computer program. Intelligent technology can greatly improve the efficiency of industrial product design in computer aided design. The intelligent technology in computer-aided technology enables the computer to automatically complete the corresponding design tasks according to the instructions of the designer [2]. Industrial product design involves not only knowledge in the field of industry, but also professional knowledge such as natural science and social science. Industrial product designers use the intelligent technology of computer to assist design, realize the technological revolution in the field of modern industrial product design, and greatly improve the development level of industrial field.

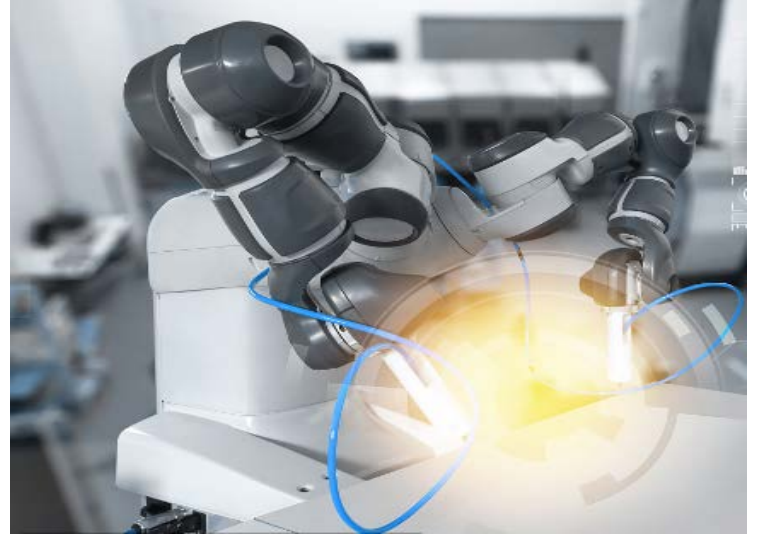

Figure 1 Computer intelligence technology

(5) The technology of material connection in computer aided technology

Computer-aided technology is based on the combination of Internet and object control under computer control. The application of Internet connection technology in the design of industrial products can make the designers of industrial products remotely control the related equipment and so on, which greatly facilitates the work of industrial product designers. When the designer has finished the design of the industrial product initially, the technology can control the industrial model to show the effect of the industrial product design, and the technology can provide the important productivity for the development of the industrial field.

\section{Application of Computer Aided Design in Industrial Product Design}

(1) Modeling aids for computer aided design in industrial product design

The application of computer aided design in industrial product design is mainly realized by modeling. In the process of computer modeling aid, the computer should have a strong modeling system. In computer aided modeling, the system functions mainly undertake the tasks of data acquisition, processing and transmission in industrial product design. In the current process of industrial design product modeling, it mainly uses CAID system to carry out industrial product modeling. The CAID system can perform all the modeling processes of industrial product design, and the execution of these processes depends on the various functional modules of the CAID system [3]. The CAID system includes software for graphic design of industrial products, software for three-dimensional design of industrial products, software for human body design of industrial products, etc. The CAID system also has the above-mentioned auxiliary functional software for industrial product design, such as software for product release, software for product research and so on, so that the modeling of computer-aided design in industrial product design can be completed effectively. Computer-aided modeling can also improve the degree of agreement between industrial product design model and designer design idea through accurate parameter design and layout design, thus reducing the modification rate and experimental cost of industrial product design, shortening the production time of product, and contributing to the healthy development of industrial product field. 


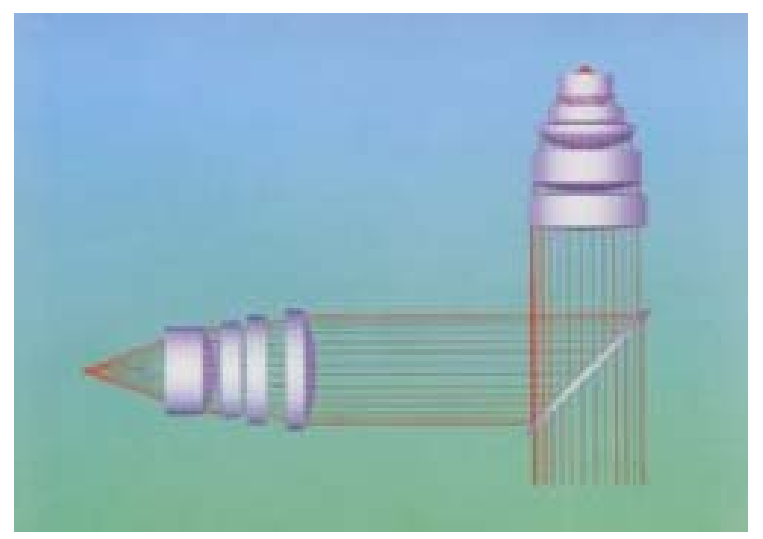

Figure 2 Computer modeling techniques

(2) Functional support of computer aided design in industrial product design

The application of computer aided design in industrial product design is also reflected in the auxiliary function of industrial design product. In the computer aided design, give full play to the various technical advantages of the computer's own characteristics, and realize the comprehensive design function of the industrial product project by establishing the industrial design network platform. Industrial design network platform can bring together a large number of design data to provide designers with the latest and sufficient design resources. In the computer function aid, using computer database and other technologies to make the combination of computer technology and industrial design more closely, the accelerated pace of innovation in industrial product design is of great significance to the development of industrial design.

\section{Development of Computer Aided Design in Industrial Product Design}

(1) VR and AR technology to assist industrial product design

VR and AR technology is a computer virtual technology, which can provide a virtual experience environment for designers in industrial product design, so that designers can master the design effect of industrial products more accurately and comprehensively. In the auxiliary development of industrial product design of VR and AR technology, the computer screen is used to present the virtual use process of industrial products, and it is able to let users experience the application feeling of industrial products, thus improving the recognition of industrial products users to the products. VR and AR technology-assisted industrial product design is still in the deep research and exploration stage, which attracts great attention of relevant research, and will also be an important direction for the development of computer-aided technology in the future.

(2)3D printing technology to assist industrial product design

$3 \mathrm{D}$ printing technology to assist industrial product design, in the process of development has been no longer limited to traditional model making and other aspects. In industrial product design, we can use 3D printing technology to standardize the production of industrial parts, and improve the economic benefit level of industrial product manufacturers. Choosing 3D printing in this way for industrial product design also helps to innovate industrial product design and improve industrial development capacity. The development of $3 \mathrm{D}$ printing technology can not be separated from the high-performance prototype printing equipment. The research of $3 \mathrm{D}$ printing technology and prototype printing equipment is also an important aspect in the development of computer aided technology. 


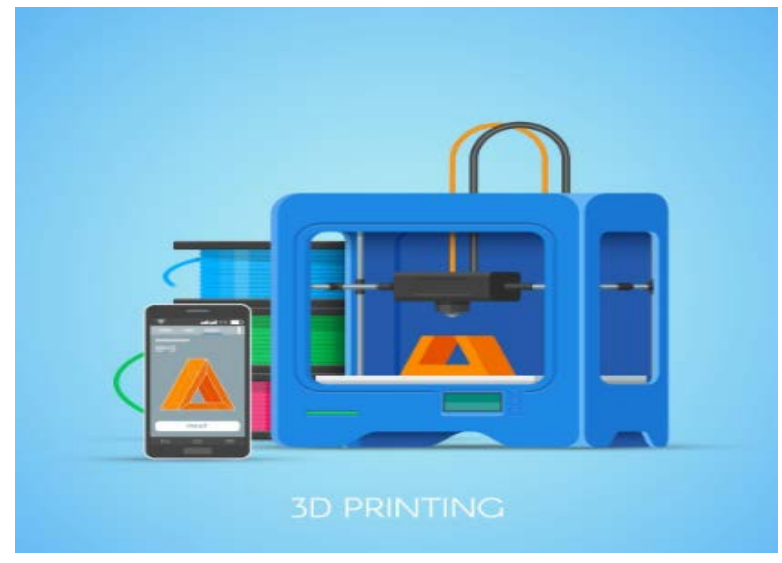

Figure 3 Computer 3D printing technology

(3) human-computer interaction technology to assist industrial product design

The human-computer interaction technology assists the industrial product design, already is a relatively popular technical form in the industrial domain. In industrial product design, the use of human-computer interaction, can form a good control of industrial product design content, but also improve the convenience of industrial product design. Industrial product designers use sound, image, action and so on to make the computer screen according to the instructions to complete the industrial product design task [4]. Human-computer interaction technology is the comprehensive utilization of computer data technology, cloud computing technology, intelligent technology, material technology and network technology. The current human-computer interaction technology is mainly realized by computer, and the development of mobile interaction technology, biometrics technology, omnidirectional perception technology and so on is not perfect, which is also the main application form of computer-aided design in industrial product design in the future, improve the interactive experience of industrial product designers and users, and realize the concept of industrial product design with user as the core.

\section{Conclusion}

With the continuous progress and development of the industrial field, if our industrial design wants to play an important role in the international industrial stage, we must improve the competitiveness of the industrial industry. Computer-aided design in the field of industrial product design, can form a great technical impetus, so that China's industrial technology to get more professional development, so that the field of industrial design into a new period of development.

\section{References}

[1] Carol Wong. The present situation and prospect of computer aided industrial design. Technological Communication, vol. 10, no. 18, pp. 116-117, 2018.

[2] Army. Research on human-computer interaction in computer aided industrial design. Shandong Industrial Technology, no. 18, pp. 40+48, 2018.

[3] Li Yu. product gene network model research oriented to industrial design. Zhejiang University of Technology, 2018.

[4] Au Ching. study of complex product industrial design systems based on semantic features. Hunan University, 2016. 